\title{
Factorial Structure Validation of the Movement Assessment Battery for Children in School-Age Children Between 8 and 10 Years Old
}

\author{
João Otacilio Libardoni dos Santos ${ }^{1}$ \\ Universidade Federal do Amazonas, \\ Manaus-AM, Brazil
}

\author{
Nilton Soares Formiga \\ Universidade Potiguar, Natal-RN, \\ Brazil
}

\author{
Gislane Ferreira de Melo \\ Universidade Católica de Brasilia, \\ Brasília-DF, Brazil
}

\author{
Maria Helena da Silva Ramalho \\ Faculdade de Tecnologia em Saúde, \\ Florianópolis-SC, Brazil
}

\author{
Fernando Luiz Cardoso \\ Universidade do Estado de Santa \\ Catarina, Florianópolis-SC, Brazil
}

\begin{abstract}
The adaptation of instruments to other cultural contexts is a complex task that requires careful planning to maintain the content and psychometric properties. One of the most used motor assessment tools in the world is the Movement Assessment Battery for Children 2ed. In this study, we evaluated the factorial organization of the MABC-2 for the age group 8-10 years from the perspective of classical and modern psychometric theory. For this purpose, a group of 350 school children in the city of Manaus (AM, Brazil) was evaluated. The factorial structure of the MABC-2 and a new factorial structure with four factors were tested. For data analysis, descriptive and inferential statistics were used. Factor analysis confirmed the original three-factor model. Based on these results, good evidences of validity were produced, based on the internal structure of the MABC-2 proposed by the original authors, confirming its ability to identify disorders in the development of coordination.
\end{abstract}

Keywords: motor coordination, performance tests, factor analysis, psychometrics

\section{Validação da Estrutura Fatorial do Movement Assessment Battery for Children em Escolares de 8 a 10 Anos}

\begin{abstract}
Resumo: A adaptação de instrumentos para outros contextos culturais é uma tarefa complexa, que exige rigor quanto à manutenção do conteúdo e das características psicométricas. Um dos instrumentos de avaliação motora mais utilizados no mundo trata-se do Movement Assessment Battery for Children 2ed. Neste estudo avaliou-se a partir da perspectiva da teoria da psicométrica clássica e moderna, a organização fatorial do MABC-2 para a faixa etária de 8 a 10 anos. Para isso foram avaliados 350 escolares da cidade de Manaus (AM, Brazil) Foram testadas a estrutura fatorial original do MABC-2 composta por três fatores e ainda uma nova estrutura fatorial do MABC-2 (4 fatores). Para análise dos dados foi utilizada a estatística descritiva e inferencial. A análise fatorial confirmou o modelo original de três fatores. Com base nestes resultados foi possível identificar boas evidências de validade baseada na estrutura interna do MABC-2 proposto pelos autores originais confirmando a sua capacidade de identificar desordens no desenvolvimento da coordenação.
\end{abstract}

Palavras-chave: coordenação motora, testes de desempenho, análise fatorial, psicometria

\section{Validación de la Estructura Factorial del Movement Assessment Battery for Children en Escolares de 8 a 10 Años}

\begin{abstract}
Resumen: La adaptación de instrumentos para otros contextos culturales es una tarea compleja que requiere rigor para mantener el contenido y las características psicométricas. Una de las herramientas de evaluación motora más utilizada en el mundo es el Movement Assessment Battery for Children 2ed. En este estudio se evaluó, desde el punto de vista de la teoría de la psicométrica clásica y moderna, la organización factor del MABC-2 para el grupo de edad de 8-10 años. Para eso, fueron evaluados 350 estudiantes de la ciudad de Manaus (AM, Brazil). La estructura factorial original del MABC-2 con tres factores y también nueva estructura factorial del MABC-2 (4 factores) se pusieron a prueba. Para el análisis de datos se utilizó la estadística descriptiva e inferencial. El análisis factorial confirmó el modelo original de tres factores. Con base en estos resultados se pudo identificar buenas evidencias de validez basada en la estructura interna del MABC-2 propuesta por los autores originales, que confirman su capacidad para identificar trastornos en el desarrollo de la coordinación.
\end{abstract}

Palabras clave: coordinación motora, test de desempeño, análisis factorial, psicometría

\footnotetext{
${ }^{1}$ Correspondence address: João Otacilio Libardoni dos Santos. Laboratório de Estudo do Desempenho Humano, Faculdade de Educação Física e Fisioterapia, Universidade Federal do Amazonas. Avenida General Rodrigo Octavio Jordão Ramos, $\mathrm{n}^{\mathbf{0}}$ 3000, Coroado. CEP 69077-000. Manaus-AM, Brasil. E-mail: jlibardoni@yahoo.com.br
}

The Movement Assessment Battery for Children Second Edition (MABC-2) (Henderson, Sugden, \& Barnett, 2007) was created and developed in the United Kingdom and is broadly used in different fields to identify children with 
Developmental Coordination Disorder (DCD) (Henderson et al., 2007; Valentini, Ramalho, \& Oliveira, 2014). This instrument of motor evaluation can be applied in children aged between 3 to 16 years old.

Due to its high efficiency, the MABC-2 (Henderson et al., 2007) has been widely adopted by clinicians and researchers in several countries (Caçola, Ibana, Romero, \& Chuang, 2016; Huau, Velay, \& Jover, 2015; Kita et al., 2016; Reynolds, Licari, Elliott, Lay, \& Williams, 2015), including in Brazil (Dornelas \& Magalhães, 2015; Maggi, Magalhães, Campos, \& Bouzada, 2014; Nascimento Junior et al., 2015), both to diagnose children with DCD and to understand the overall motor development of these children.

Because of this widespread use around the world, out of its creative context, several studies have tested psychometric aspects of MABC to ensure that the original essence of the instrument is maintained, i.e. that the instrument can measure what it originally purports to measure, even in other cultural contexts. Miyahara et al. (1998) examined the test's suitability in 133 Japanese children aged 7-11 years. Their performance on each item was compared to that of American children of the same age, who constituted the standardization sample. The results indicated that the items of dynamic balance favored Japanese children, while those of manual dexterity favored the American children. Chow, Hsu, Henderson, Barnett, \& Lo (2006) compared the MABC Test scores of 799 children from Hong Kong and Taiwan with those of their peers from the standardization sample. Age was found to have a significant effect on children's scores, but both within-culture and cross-cultural differences were statistically significant when all items of the MABC were examined simultaneously. Moreover, a high percentage (92\%) of the 6-year-old Chinese children obtained perfect scores on the item "walking along a line with heels raised", causing a "ceiling effect" (Venetsanou et al., 2011).

Van Waelvelde, De Weerdt, De Cock, and Smits-Engelsman (2004), in a study in Belgium, investigated the concurrent validity of the total impairment score and some of the item scores of the second and third age band of the $\mathrm{MABC}$ test and identified that some items lack variance and do not differentiate sufficiently between the children, although the investigated group was heterogeneous. Some items have a "ceiling effect", even for children with fairly poor motor skills, again resulting in a lack of discriminative power. As there are relatively few items in the MABC, it is important for each item to have discriminative power. The authors suggest adjustments for the items "Hopping on mats" and "Walking heel to toe forwards" in the second age band to allow better differentiation among children.

Ellinoudis et al. (2011) examined the reliability (test-retest e internal consistency) and validity (construct) of age band 1 of the Movement Assessment Battery for Children - Second Edition in Greek preschool children and concluded that the MABC-2 is a reliable and valid tool for the assessment of movement difficulties in preschool children. Although Cronbach's alpha coefficient values were moderate, the high test-retest reliability coefficients for almost all test items and the good construct results indicated that the MABC-2 is a reliable tool. A validation process should be confirmed by more than one approach though, and using multiple techniques (Nunnally \& Bernstein, 1994). The authors also point out that future research efforts are required to provide evidence of reliability and validity in different groups of children with or without movement difficulties in all age bands.

Hua, Gu, Meng, and $\mathrm{Wu}$ (2013) examined the validity (criteria-related, content and construct) and reliability (Interrater and test-retest, internal consistency) of age band 1 of the Movement Assessment Battery for Children-Second Edition (MABC-2) in preparing for its standardization in mainland China. They concluded that the reliability and validity of age band 1 of MABC- 2 were fair in this study based on a large sample. Part of the items needed to be adjusted though, in order to improve the test's psychometric properties when used in Chinese children.

As the MABC Test consists of relatively few items, they should be valid by themselves for the information of the assessment using that instrument to be sound (Venetsanou et al., 2011). Nevertheless, in a number of the aforementioned studies, several shortcomings at the item level have been found. Specifically, "ceiling effects" have been noticed in the items "jumping in squares", "hopping in squares" (Miyahara et al., 1998; Van Waelvelde et al., 2004), "balancing a ball on a plate" (Miyahara et al., 1998), "walking along a line with heels raised" (Chow et al., 2006; Van Waelvelde et al., 2004), "heel-to-toe walking" and "cutting out elephant" (Miyahara et al., 1998), whereas the validity of the items "throwing a ball at the wall and catching it" and "balancing a ball on a plate" has been characterized as questionable (Van Waelvelde et al., 2004). The failure of these tasks to give valid information about children's motor performance is an issue to be considered. Researchers and clinicians sometimes interpret the results of the MABC Test at the item level and the aforementioned findings support this interpretation (Venetsanou et al., 2011).

Considering the factorial structure, Schulz, Henderson, Sugden, and Barnett (2011) analyzed the structure validity of the Movement Assessment Battery for Children - Second Edition (MABC-2) in a group of children in the United of Kingdom and a group of UK children. They found that the tasks proposed for the age group of 7 to 10 years old should be reviewed especially in the dimension of balance, even proposing the division of this size in static equilibrium (One-board balance task) and dynamic equilibrium (walking heel-to-toe forwards and hopping on mats task). In the same perspective, Wagner, Kastner, Petermann, and Bös (2011) also tested the factorial analyses of the Second Band of the MABC-2 in a German sample and concluded that, overall, the MABC-2 score was efficient, although the model proved problems in its substructures. According to the authors, discriminant validity and convergent validity related tasks around the "bicycle trail", "hold the ball with both hands", "walking joining heel to toe" and "jump on one foot" (band 2) had doubtful substructures, suggested that these tasks should be eliminated. These variables were not measuring the same construct as the other tasks in the same dimension as proposed by the instrument. 
It is important to note that the psychometric aspects of MABC-2 have been tested in Brazil, but only in two states. Valentini et al. (2014) translated the MABC-2 into the Brazilian-Portuguese language and examined the reliability (inter-rater, intra-rater, test-retest and internal consistency) and validity (Content and face, Construct and Criterion and Concurrent) of the translated MABC-2 for Brazilian children from six different cities in two states in the South of Brazil (Rio Grande do Sul and Santa Catarina) and they demonstrated for the first time that the MABC-2 is valid in Brazil. Thus, the Brazilian-Portuguese Version of the MABC-2 was created and rigorously tested with respect to its reliability and face, content, criterion and construct validity. Still, the authors highlight that the MABC-2 proved to be accurate and valid for Brazilian children.

Therefore, the authors make clear that, although a large sample size was used in this investigation, we should consider the cultural diversity of motor experiences found in different states and regions in Brazil. As seen in several large countries, children originating from different regions certainly have a distinctive (or context-specific) motor repertoire, especially those children at the age range targeted in the MABC-2. Hence, generalization of these findings is currently limited; future research should replicate and extend our results to children from other states in Brazil.

This fact is due to the continental size of our country, with high levels of asymmetry and social inequality, different motivational characteristics, different mechanical and anthropometric aspects, familiarity or not with the particular motor task and different meanings given by the individual to that task, which can impair the essence of the instrument (Payne \& Isaacs, 2007). This is a major problem because the diagnosis of DCD, similar to other movement disorders, depends on the use of reliable and valid instrument (Netelenbos, 2005; Wiart \&
Darrah, 2001; Yun \& Ulrich, 2002).

Despite its wide acceptance around the world and the potential of MABC-2 as a tool to screen children with probable $\mathrm{DCD}$, it is necessary to check its validity in different regions of Brazil, even in specific aspects. It is understood, based on the aforementioned studies, that the instrument can suffer interference in its structure (validity and reliability) compared to the adapted versions from different socioeconomic environments with ethnic and cultural issues (Pasquali, 2001; Valentini et al., 2014).

Thus, the main goal of this study was to evaluate the factorial structure of the MABC-2, from the perspective of classical and modern psychometric theory, in a group of school-aged children in the North of Brazil, in the age range between 8 and 10 years, based on the original MABC-2 factorial structure with three factors (Henderson et al., 2007), and also in the newly proposed four-factor structure of the MABC-2, as suggested by Schulz et al. (2011).

\section{Method}

\section{Participants}

A total of 350 children (162 boys and 188 girls) aged between eight and ten years ( 8 years $=118$ children, 9 years $=134$ children and 10 years $=98$ children) participated in the study. An Informed Consent Term signed by the parents or the custodial caregivers and having no known history of physical and/or learning disabilities were considered as inclusion criteria. The research context involved three schools, being two public and one private school, selected according to the availability of participation, located in the city of Manaus, in the State of Amazonas. Table 1 provides detailed information about the participants.

Table 1

Sample $N$ and MABC-2 score standards by age $(n=350)$

\begin{tabular}{|c|c|c|c|c|c|c|}
\hline \multirow{3}{*}{$\mathrm{AB}$} & \multirow{3}{*}{ Age } & \multirow{3}{*}{$n$} & \multicolumn{4}{|c|}{ MABC-2 } \\
\hline & & & \multicolumn{3}{|c|}{ Standard Scores X $(S D)$} & \multirow{2}{*}{ Standard Scores Total Test } \\
\hline & & & Manual Dexterity & Aiming and Catching & Balance & \\
\hline \multirow{3}{*}{ AB2 } & 8 & 118 & $9.98(2.75)$ & $7.29(3.14)$ & $8.69(2.83)$ & $8.40(2.50)$ \\
\hline & 9 & 134 & $9.95(2.52)$ & $8.63(2.71)$ & $8.33(2.88)$ & $8.58(2.50)$ \\
\hline & 10 & 98 & $10.50(2.12)$ & $8.43(2.79)$ & $7.82(2.98)$ & $8.51(2.76)$ \\
\hline
\end{tabular}

According to the economic conditions (Associação Brasileira de Empresas de Pesquisa [ABEP], 2008), 1.4\% of the students belonged to social class A2, $8 \%$ to social class B1, $27.1 \%$ to social class $\mathrm{B} 2,35.7 \%$ to social class $\mathrm{C} 1,17.4 \%$ to social class $\mathrm{C} 2,8.6 \%$ to social class $\mathrm{C}$ and $1.4 \%$ to social class D. Manaus is a Brazilian city, the state capital of Amazonas and the main financial, corporate and economic center in Northern Brazil. It is located at the confluence of the Negro and Solimões rivers and is the sixth richest city in Brazil. The city is the eleventh largest Brazilian city in terms of population, with $2,478,088$ inhabitants isolated in the middle of a rain forest, representing $1.22 \%$ of the total Brazilian population.

\section{Instruments}

The children were assessed using the MABC-2 (Henderson et al., 2007). The MABC-2 is designed to assess motor impairments of children in different age bands (AB) from 3 to 16 years old (AB1: 3-6 years; AB2: 7-10 years; AB3: 11-16 years) and consists of two distinct and complementary sections. The first section of the test corresponds to a questionnaire in the form of an observational motor behavior checklist (checklist) and the other consists of a battery of motor tests. The tests that make up the instrument enable the assessment of the coordinative disorders of child 
development in different environments. According to the authors, these instruments are complementary in the sense of identifying and evaluating motor disorder in children (Henderson et al., 2007).

The second section of the test, which is the battery of motor skills, is organized in three parts, according to the age: Band 1 related to children three to six years of age; Band 2 refers to children aged seven to ten years; and Band 3 is relevant for children of eleven to sixteen years old. Each band has specific tasks according to the age and encompasses three dimensions of motor behavior (Manual Dexterity, Throwing and Hold and Balance). After the implementation of the tasks, the raw scores are converted to standard scores. The scores are added up within each category of ability, resulting in the total score of the motor components. Adding up the latter values results in the standard test score or the overall outcome score.

Both the standard scores and the total scores are compared to a table of percentiles, which permit classifying the motor performance of children. A higher score indicates a higher standard score and thus a higher percentile. Thus, the test ranking is based on percentile values where values $\leq 5$ th percentile indicate probable DCD; Values between the 6 th and the 15 th percentile indicate that the child is at risk of $\mathrm{DCD}$, values $\geq 16$ th percentile suggest that the child does not have DCD (Henderson et al., 2007).

This study tested the factorial structure in Band 2 . Band 2 comprises eleven tasks, which are: Placing Pegs for preferred hand (MD1P), Placing Pegs for non-preferred hand (MD1NP), Threading lace (MD2), Drawing trail 2 (MD3), related to the Manual Dexterity dimension (MD); Catching with two hands (AC1), Throwing beanbag onto mat (AC2) in the scale Aiming and Catching (AC), and One-board balance for right foot (BAL1R), One-board balance for right foot (BAL1L), Walking heel to toe forwards (BAL2), Hopping on mats 2 for right foot (BAL3R) and Hopping on mats 2 for left foot (BAL3L) for the Balance dimension (BAL). The raw results of the tasks include different strategies, such as "time in seconds", "number of errors" and "number of correct trials", depending on the tasks structure. For some tasks, a higher score indicates a better performance (e.g., number of seconds balanced correct number of hops) while, for others, a lower score indicates a better performance (e.g. completion time and the number of errors).

The application of the MABC-2 test strictly followed the protocol stipulated by the instrument authors, according to the age group (Henderson et al., 2007).

\section{Procedure}

In order to achieve the objective of the study, the following procedures were performed: (a) research project previously approved by the Ethics Committee for Research with Human Beings; (b) contact with the Principals of the schools to release the space to collect data and to clarify the research objectives; (c) sending the Informed Consent to parents and / or guardians of children at the school; (d) schedule date of data collection along with the direction of the selected schools; (e) preparation of data collection environment; (f) data collection on the date scheduled.

Data collection. Motor assessments of the children were conducted individually at the schools according to the availability of access to students, as established by the school and teachers. The application of motor tasks carefully followed the protocol stipulated by the instrument authors (Henderson et al., 2007) and took place in the morning and afternoon in the spaces provided by the school.

The children were assessed individually during regular class hours, except during Physical Education classes. Two individuals previously trained with one year of experience in the application conducted the evaluations. The entire assessment takes an average 30 minutes for each child to complete.

Data analysis. For data analysis, we used version 21.0 of SPSS for Windows. Descriptive statistics (central trend and dispersion measures) and Pearson's correlation ( $\mathrm{r}$ ) coefficients were calculated to evaluate the factorial structure of MABC2 in the samples. In addition, confirmatory factor analysis was undertaken in statistical software AMOS 21.0. Thus, we sought to evaluate the consistency of the factor structure of the MABC-2 model, previously proposed by Henderson et al. (2007) and also the model proposed by Schulz et al. (2011). Therefore, the covariance matrix that adopted the ML estimator (Maximum Likelihood) was considered as input.

This type of statistical analysis is more detailed and accurate, so that the empirical and theoretical structure and the hypothesized model can be tested; this analysis presents some indexes for assessing the fit of the proposed model (Bilich, Silva, \& Ramos, 2006; Byrne, 1989; Hair, Anderson, Tatham, \& Black, 2005; Kelloway, 1998; Tabachnick \& Fidell, 1996; van de Vijver \& Leung, 1997). Next, these indicators will be presented:

(1) The $\chi^{2}$ (chi-square) tests the probability of whether the theoretical model fits the data: the higher the value of the $\chi^{2}$, the worse the adjustment. However, it is seldom used in the literature (Bilich et al., 2006; Byrne, 1989; Hair et al., 2005; Kelloway, 1998; Tabachnick \& Fidell, 1996; van de Vijver \& Leung, 1997). Its ratio is most frequently considered in relation to the degrees of freedom $\left(\chi^{2} / \mathrm{df}\right)$. In this case, values up to 3 indicate an appropriate adjustment.

(2) Goodness-of-Fit Index (GFI) and Adjusted Goodness-of-Fit Index (AGFI) are analogous to the multiple regression $\mathrm{R}^{2}$ and thus indicate the proportion of the variancecovariance matrix of the data explained by the model. The values of these indicators range from 0 to 1 , and values in the region of 0.80 and 0.90 or higher indicate satisfactory adjustment (Bilich et al., 2006; Byrne, 1989; Hair et al., 2005; Kelloway, 1998; Tabachnick \& Fidell, 1996; van de Vijver \& Leung, 1997).

(3) The Root-Mean-Square Error of Approximation (RMSEA), with its $90 \%$ confidence interval $(90 \% \mathrm{CI})$ is considered an indicator of "bad" adjustment, i.e. high values indicate an unadjusted model. It is assumed as ideal that the RMSEA is between 0.05 and 0.08 , accepting values up to 0.10 .

(4) The PCLOSE is regarded as a more weighted indicator that tests the null hypothesis of RMSEA, and this hypothesis must be rejected when its value is close to zero, a condition that suggests lack of model fit. Thus, Pclose $>0.05$ is recommended as indicative of an adjusted model. 
(5) The Comparative Fit Index (CFI) compares the estimated model to the null model in a general way, considering values closer to one as satisfactory adjustment indicators.

(6) Tucker-Lewis Index (TLI) represents the parsimony measured between the contents of the proposed model and the null model. Ranges from zero to one, indices superior to 0.90 being considered acceptable.

(7) The Expected Cross-Validation Index (ECVI) and the Akaike Information Criterion Consistent (CAIC) indicators are generally used to assess the suitability of a particular model over another. Low-ECVI values and CAIC express the model with the best fit.

For data analysis, the raw data of each MABC-2 motor task were used, following the guidelines stipulated by the authors (Henderson et al., 2007).

\section{Ethical Considerations}

All the procedures adopted in this study followed the guidelines defined in National Health Council (CNS) Resolution 196/96 (CNS 1996) for research on human subjects, and the study was approved by the Ethics Committee for Research with Human Beings of the Federal University of Amazonas under number 114 687. The participants' responsible caregivers were requested to sign an Informed Consent term and anonymity and confidentiality were assured.

\section{Results}

Initially, the results will be presented by introducing the associations between the items in each of the three dimensions proposed (Manual Dexterity factor, Aiming and catching factor and Balance factor) in the MABC 2 and the sum of its scores. The assessment of the representativeness of the item contents is displayed in Table 2 for the Manual Dexterity factor (MD), where all the correlations were positive for the items and the total MABC-2 score. Furthermore, in Table 2, the correlation of the items "Aiming and Catching" factor and total scale score (MABC2) is observed. In this table, significantly positive correlations are revealed (factor-items and total score-items). In addition, a significant correlation exists between the items in the Balance factor and the total score of the MABC-2, where all items were related to their respective factor and the MABC-2 (total score).

Table 2

Correlation scores between items-factor Aiming and catching and the total score of $M A B C-2$

\begin{tabular}{|c|c|c|c|}
\hline Factor & Item & MABC-2 & Item-Factor \\
\hline \multirow{4}{*}{ Manual Dexterity } & Placing Pegs for preferred hand (MD1P) & $0.30^{*}$ & $0.73 *$ \\
\hline & Placing Pegs for non preferred hand (MD1NP) & $0.35^{*}$ & $0.78 *$ \\
\hline & Threading lace (MD2) & $0.31 *$ & $0.72 *$ \\
\hline & Drawing trail 2 (MD3) & 0.30 & $0.36^{*}$ \\
\hline \multirow{2}{*}{ Aiming and catching } & Catching with two hands (AC1) & $0.31^{*}$ & $0.88 *$ \\
\hline & Throwing beanbag onto mat (AC2) & $0.33 *$ & $0.72 *$ \\
\hline \multirow{5}{*}{ Balance } & One-board balance for right foot (BAL1R) & $0.73^{*}$ & $0.82 *$ \\
\hline & One-board balance for left foot (BAL1L) & $0.72 *$ & $0.82 *$ \\
\hline & Walking heel to toe forwards (BAL2) & $0.34^{*}$ & $0.47 *$ \\
\hline & Hopping on mats 2 for right foot (BAL3R) & $0.37 *$ & $0.36^{*}$ \\
\hline & Hopping on mats 2 for left foot (BAL3L) & $0.38 *$ & $0.35^{*}$ \\
\hline
\end{tabular}

Note. ${ }^{*} \mathrm{p}<0.01 ;$ MABC-2 $=$ Sum total items.

By checking the desired factor structure in relation to the two proposed models (Model $1=$ original factorial organization (eleven items distributed among three factors) proposed by Henderson et al. (2007); Model 2 = alternative organization (eleven items and four factors) proposed by Schulz et al. (2011) can be observed and compared in Table 3 with its respective indicators tested.

Table 3

Psychometric indicators of the different factor structures of the MABC-2

\begin{tabular}{ccccccccccc}
\hline & \multicolumn{10}{c}{ Psychometric indicators of the MABC-2 } \\
\hline & cfd/2 & GFI & AGFI & CFI & TLI & RMSEA & PCLOSE & CAIC & ECVI \\
Model 1 & 3.99 & 0.91 & 0.86 & 0.72 & 0.65 & $0.09(0.08-0.11)$ & 0.01 & 326.39 & $0.63(0.52-0.76)$ \\
Model 2 & 2.82 & 0.96 & 0.94 & 0.97 & 0.98 & $0.06(0.01-0.07$ & 0.95 & 237.54 & $0.31(0.28-0.35)$ \\
Model 3 & 1.97 & 0.98 & 0.97 & 1.00 & 1.00 & $0.01(0.00-0.04)$ & 0.99 & 207.27 & $0.23(0.23-0.28)$ \\
\hline
\end{tabular}

Note. Model 1: One-factor organization; Model 2: Original factorial organization proposed by Henderson et al. (2007); Model 3: Alternative organization proposed by Schulz et al. (2011); Fit Index; * TLI Tucker-Lewis Index; * RMSEA The Root-Mean-Square Error of Approximation; * PCLOSE The PCLOSE; * CAIC Akaike Information Criterion Consistent Indicator; * ECVI The Expected Cross-Validation Index. 
Considering those indicators (Table 4), it was observed that all saturations (Lambdas, $\lambda$ ) were within the expected range $|0-1|$ and statistically different from zero ( $\mathrm{t}>1.96$, $p<.05$ ), indicating no problems with the proposed estimate for the evaluation of the instrument; this condition confirms the existence of the original three-factor model over the later hypothesized model (Table 4). With respect to the MD, AC and BAL constructs, a positive association Phi $(\phi)$ was observed between $\mathrm{AC}$ and $\mathrm{BI}(\phi=0.48)$, but a negative association between MD and $\mathrm{AC}(\phi=-0.53)$ and MD and $\mathrm{BI}(\phi=-0.48)$.

Table 4

M-ABC2 Factorial Structure

\begin{tabular}{|c|c|c|c|c|c|}
\hline$\xi_{1}($ construct $)$ & $\chi$ (variables) [items] & $\lambda$ & $\varepsilon$ (errors) & $\mathrm{CC}$ & VME \\
\hline \multirow{4}{*}{$\mathrm{MD}$} & MD1P & 0.63 & 0.39 & \multirow{4}{*}{0.73} & \multirow{4}{*}{0.53} \\
\hline & MD1NP & 0.73 & 0.53 & & \\
\hline & MD2 & 0.46 & 0.31 & & \\
\hline & MD3 & 0.26 & 0.37 & & \\
\hline \multirow{2}{*}{$\mathrm{AC}$} & $\mathrm{AC} 1$ & 0.64 & 0.41 & \multirow[b]{2}{*}{0.63} & \multirow[b]{2}{*}{0.46} \\
\hline & $\mathrm{AC} 2$ & 0.47 & 0.32 & & \\
\hline \multirow{5}{*}{ BAL } & BAL1R & 0.43 & 0.38 & \multirow{5}{*}{0.76} & \multirow{5}{*}{0.51} \\
\hline & BAL1F & 0.34 & 0.32 & & \\
\hline & BAL2 & 0.43 & 0.38 & & \\
\hline & BAL3R & 0.62 & 0.38 & & \\
\hline & BAL3F & 0.59 & 0.35 & & \\
\hline
\end{tabular}

Note. $\xi 1=$ theoretical construct; $\lambda=$ factor scores of the structure; $\varepsilon$ (error) $=$ structure measurement errors; $\chi=$ variables (items).

Regarding the validity of this construct, both the composite reliability $(\mathrm{CC})$ and the extracted average variance (VME) were calculated; in the first indicator, is required that the score level superior to 0.70 is required while, for the second indicator, the score should be superior to 0.50 (Campana, Tavares, \& Silva, 2009; Hair et al., 2005). It was observed that, for the MD, AC and BAL dimensions of the MABC-2, composite reliability (CC) and the extracted average variance (VME) were above the levels required in the statistical literature (respectively, CC corresponded to $0.73,0.63$ and 0.76 ; VME was equal to 0.53 , $0.46,0.51$, Table 4 ), a condition that demonstrates the reliability and convergent validity of the construct used in this instrument. Overall, although justifying the adequacy of the factorial structure of MABC-2, which proved to be reliable for our sample, we called attention to the $\mathrm{AC}$ factor, which presented $\mathrm{CC}$ and $\mathrm{VME}$ below expectations. A possible explanation for this result is due to the amount of the items in this factor, as psychometric indicators are related to the amount of items that make up the factor.

\section{Discussion}

The main goal in this study was to evaluate the factorial structure of the MABC-2, from the perspective of the classical and modern psychometric theory, in a group of school-aged children in the North of Brazil, with the ranging age between 8 till 10 years based on the original MABC-2 factorial structure with three factors (Henderson et al., 2007), and also in the newly proposed four-factor structure, as suggested by Schulz et al. (2011).

When analyzing the representativeness of the items' content, the main objective was to verify the behavior-domain representation of that test in the samples of children studied. We systematically sought to assess the relation between the theoretical test and the situations specified in the items, and how they represent the expected aspects (Cunha, 2000; Pasquali, 2003). Thus, it was decided to present the results based on the correlational organization of the items and their factors.

It was observed that the items-factor and MABC-2 full-score item correlations were higher than expected in the statistical literature discussed in this article (Byrne, 1989; Hair et al., 2005) (Table 2), which suggests a good representative power-domain behavior in relation to MABC-2 in the sample of children studied. Thus, theoretically and empirically, the MABC-2 test and the specified situation items confirm the representation of the aspects hypostasized for band 2 under analysis. Recently, Kita et al. (2016) found good factorial validity for the original model proposed by Henderson et al. (2007) in a study of 132 Japanese children ( 84 boys and 48 girls) between 7.0 and 10.8 years of age, in which each of the three components had its constituent items.

An important aspect to highlight is the correlation of the MD3 motor task, since it presented low correlation in this study (Table 2). This task had being highlighted in the study by Schulz et al. (2011), where they found that it was the only task to present a substantial loading $<0.50$ in the respective factor in Band 2.

The analysis of the representativeness of the content has contributed to sustain the MABC-2 factorial organization in this sample. Therefore, we chose to evaluate, through confirmatory factor analysis, the same factorial structure (Table 2), as observed in other papers (Kita et al., 2016). Therefore, we tried to compare the psychometric indicators of the original factorial organization to the alternative organization proposed by Schulz et al. (2011), which suggested the exclusion of one item (Drawing trail 2).

Without establishing the covariance (phi, $\varphi$ ) between the factors, the results revealed that the set of quality indicators 
were better for the original model, which is composed of eleven items, distributed among three factors (MD with four items, AC with two items, and BAL with five items). The statistical indicators are adequate as recommendations made in the statistical literature (Byrne, 1989; Lattin, Carroll, \& Green, 2011; van de Vijver \& Leung, 1997) (Table 2).

However, is important to look at model 2, which was proposed by Schulz et al. (2011), and emphasize the subdivision of the BAL factor into two sub-factors (static and dynamic balance sheet), also suggesting the exclusion of an item (Drawing trail 2). Although this model demonstrates very good psychometric indicators, we should be careful to suggest it is the better model, because its indicators are tangent to the required statistical standard for the realization of this calculation, which states that such results should be above 1.00. Nevertheless, we need to consider the results of that model, specifically the $\chi^{2} / \mathrm{df}$ (which tests the probability that the theoretical model fits the data), appointing errors and lack of methodological and theoretical parsimony.

Based on these results, this study gave psychometric support to the three structural dimension of MABC-2 proposed by Henderson et al. (2007). However, the results went beyond, suggesting a reduced measuring instrument, which contributes to improve the theoretical proposition and the measurement of the child's motor skills.

If you are searching for a screening instrument to diagnose disorders in the development of motor coordination, we suggest using the original scale, as it showed the best psychometric indicators for this purpose. Since we did not use another concurrent instrument to diagnose the motor disorders in this study, we cannot guarantee that the shorter version will preserve the same accuracy in detecting the motor disorders.

The practical implications of this study are: The original model of $M A B C-2$ built in another cultural context maintains its psychometric properties when applied in a Brazilian school group from the state of Amazon, which ensures that the instrument has good evidences of validity based on its internal structure. It has been demonstrated that it assesses what is originally proposed (disorders in the development of coordination), even in another cultural context. The MABC2 is an assessment tool of disorders in the development of coordination, suitable to be applied in Brazilian populations that have characteristics similar to the study participants.

This study has the following limitations, which must be considered in studies hereafter: the age group studied does not include all of the ages in Band 2. For example, seven-yearold children were not included due to sample availability. The sample was not selected randomly, but according to the availability of access to participants, which reduced the generalizability of the study results for the North of the country, or even for the state of Amazonas as whole.

\section{References}

Associação Brasileira de Empresas de Pesquisa. (2008). Critério de Classificação Econômica Brasil [Criteria of Economic Classification Brazil]. Retrieved from http://www.abep.org/ Servicos/Download.aspx?id=05
Bilich, F., Silva, R., \& Ramos, P. (2006). Análise de flexibilidade em economia da informação: Modelagem de equações estruturais [Flexibility analysis in thein formation economy: Structural equation modeling]. Journal of Technology and Information Systems Management, 3(2), 93-122. Retrieved from http://www.scielo.br/pdf/jistm/v3n2/03.pdf

Byrne, B. M. (1989). Structural equation modeling with LISREL, PRELIS and SIMPLIS: Basic concepts, applications and programming. Mahwah, NJ: Lawrence Erlbaum.

Caçola, P. M., Ibana, M., Romero, M., \& Chuang, J. (2016). The effectiveness of a group motor skill intervention program in children with developmental coordination disorder: Program frequency matters. The Internet Journal of Allied Health Sciences and Practice, 14(1), 4. Retrieved from http://nsuworks.nova.edu/cgi/viewcontent. cgi?article $=1567 \&$ context $=$ ijahsp

Campana, A. N., Tavares, M. C., \& Silva, D. (2009). Modelagem de equações estruturais: Apresentação de uma abordagem estatística multivariada para pesquisas em Educação Física. Motricidade, 5(4), 59-80. Retrieved from http://www.scielo. mec.pt/pdf/mot/v5n4/v5n4a06.pdf

Chow, S. M., Hsu, Y.-W., Henderson, S. E., Barnett, A. L., \& Lo, S. K. (2006). The movement ABC: A cross-cultural comparison of preschool children from Hong Kong, Taiwan, and the USA. Adapted Physical Activity Quarterly, 23(1), 3148. doi:10.1123/apaq.23.1.31

Cunha, J. A. (2000). Psicodiagnóstico-V [Psychodiagnosis-V] (5th ed.). Porto Alegre, RS: Artes Médicas.

Dornelas, L. F., \& Magalhães, L. C. (2016). Desempenho funcional de escolares que receberam diagnóstico de atraso do desenvolvimento neuropsicomotor até os dois anos. Revista Paulista de Pediatria, 34(1), 78-85. doi:10.1016/j. rppede.2015.10.001

Ellinoudis, T., Evaggelinou, C., Kourtessis, T., Konstantinidou, Z., Venetsanou, F., \& Kambas, A. (2011). Reliability and validity of age band 1 of the movement assessment battery for children - second edition. Research in Developmental Disabilities, 32(3), 1046-1051. doi:10.1016/j.ridd.2011.01.035

Hair, J. F., Jr., Anderson, R. E., Tatham, R. L., \& Black, W. (2005). Análise multivariada de dados [Multivariate data analysis] (A. S. Sant'Anna \& A. Chaves Neto, Trads., 5a ed.). Porto Alegre, RS: Bookman.

Henderson, S. E., Sugden, D. A., \& Barnett, A. L. (2007). The Movement Assessment Battery for Children-2: Examiner's manual (2nd ed.). London, United Kingdom: Pearson.

Hua, J., Gu, G., Meng, W., \& Wu, Z. (2013). Age band 1 of the Movement Assessment Battery for Children- second edition: Exploring its usefulness in mainland China. Research in Developmental Disabilities, 34(2), 801-808. doi:10.1016/j. ridd.2012.10.012

Huau, A., Velay, J. L., \& Jover, M. (2015). Graphomotor skills in children with developmental coordination disorder (DCD): Handwriting and learning a new letter. Human Movement Science, 42, 318-332. doi:10.1016/j.humov.2015.03.008 
Kelloway, E. K. (1998). Using LISREL for structural equation modeling: A researcher's guide. Thousand Oaks, CA: Sage.

Kita, Y., Suzuki, K., Hirata, S., Sakihara, K., Inagaki, M., \& Nakai, A. (2016). Applicability of the Movement Assessment Battery for Children-Second Edition to Japanese children: A study of the Age Band 2. Brain \& Development, 38(8), 706713. doi:10.1016/j.braindev.2016.02.012

Lattin, J., Carroll, J. D., \& Green, P. E. (2011). Análise de dados multivariados (H. Avritscher, Trad.). São Paulo, SP: Cengage Learning.

Maggi, E. F., Magalhães, L. C., Campos, A. F., \& Bouzada, M. C. F. (2014). Preterm children have unfavorable motor, cognitive, and functional performance when compared to term children of preschool age. Jornal de Pediatria, 90(4), 377-383. doi:10.1016/j.jped.2013.10.005

Miyahara, M., Tsujii, M., Hanai, T., Jongmans, M., Barnett, A., Henderson, S. E., ... Kageyama, H. (1998). The Movement Assessment Battery for Children: A preliminary investigation of its usefulness in Japan. Human Movement Science, 17(4-5), 679-697. doi:10.1016/S0167-9457(98)00018-9

Nascimento Junior, J. R. A., Ferreira, L., Vissoci, J. R. N., Silva, P. N., Caruzzo, N. M., \& Vieira, J. L. L. (2015). Nível socioeconômico e affordances do ambiente domiciliar: Implicações para o desempenho motor infantil. Revista da Educação Física/UEM, 25(4), 651-662. doi:10.4025/ reveducfis.v25i4.26529

Netelenbos, J. B. (2005). Teachers' ratings of gross motor skills suffer from low concurrent validity. Human Movement Science, 24(1), 116-137. doi:10.1016/j.humov.2005.02.001

Nunnally, J. C., \& Bernstein, I. H. (1994). The assessment of reliability. In Psychometric theory (pp. 248-292). New York, NY: McGraw-Hill.

Pasquali, L. (2001). Técnicas de Exame Psicológico: TEP: Manual. São Paulo, SP: Casa do Psicólogo.

Pasquali, L. (2003). Psicometria: Teoria dos testes na psicologia e na educação [Psychometrics: Theory test in psychology and education]. Petrópolis, RJ: Vozes.

Payne, V. G., \& Isaacs, L. D. (2007). Desenvolvimento motor humano: Uma abordagem vitalícia (G. Taranto, Trad., 6a ed.). Rio de Janeiro, RJ: Guanabara Koogan.

Reynolds, J. E., Licari, M. K., Elliott, C., Lay, B. S., \& Williams, J. (2015). Motor imagery ability and internal representation of movement in children with probable developmental coordination disorder. Human Movement Science, 44, 287298. doi:10.1016/j.humov.2015.09.012

Schulz, J., Henderson, S. E., Sugden, D. A., \& Barnett, A. L. (2011). Structural validity of the Movement ABC-2 test: Factor structure comparisons across three age groups. Research in Developmental Disabilities, 32(4), 1361-1369. doi:10.1016/j.ridd.2011.01.032

Tabachnick, B. G., \& Fidell, L. S. (1996). Using multivariate statistics. Needham Heights, MA: Allyn \& Bacon.
Valentini, N. C., Ramalho, M. H., \& Oliveira, M. A. (2014). Movement Assessment Battery for Children-2: Translation, reliability, and validity for Brazilian children. Research in Developmental Disabilities, 35(3), 733-740. doi:10.1016/j. ridd.2013.10.028

van de Vijver, F. J. R., \& Leung, K. (1997). Methods and data analysis for cross-cultural research. Thousand Oaks, CA: Sage.

Van Waelvelde, H., De Weerdt, W., De Cock, P., \& SmitsEngelsman, B. C. M. (2004). Aspects of the validity of the Movement Assessment Battery for Children. Human Movement Science, 23(1), 49-60. doi:10.1016/j. humov.2004.04.004

Venetsanou, F., Kambas, A., Ellinoudis, T., Fatouros, I., Giannakidou, D., \& Kourtessis, T. (2011). Can the Movement Assessment Battery for Children-Test be the "gold standard" for the motor assessment of children with Developmental Coordination Disorder? Research in Developmental Disabilities, 32(1), 1-10. doi:10.1016/j.ridd.2010.09.006

Wagner, M. O., Kastner, J., Petermann, F., \& Bös, K. (2011). Factorial validity of the Movement Assessment Battery for Children-2 (age band 2). Research in Developmental Disabilities, 32(2), 674-680. doi:10.1016/j.ridd.2010.11.016

Wiart, L., \& Darrah, J. (2001). Review of four tests of gross motor development. Developmental Medicine \& Child Neurology, 43(4), 279-285. doi:10.1111/j.1469-8749.2001.tb00204.x

Yun, J., \& Ulrich, D. A. (2002). Estimating measurement validity: A tutorial. Adapted Physical Activity Quarterly, 19(1), 32-47. doi:10.1123/apaq.19.1.32

João Otacilio Libardoni dos Santos is Professor at the Universidade Federal do Amazonas.

Nilton Soares Formiga is Professor of the Universidade Potiguar.

Gislane Ferreira de Melo is Professor at the Universidade Católica de Brasília.

Maria Helena da Silva Ramalho is Director of Teaching at the Faculdade de Tecnologia em Saúde.

Fernando Luiz Cardoso is Professor at the Universidade do Estado de Santa Catarina.

Received: Oct. 10, 2015

1st Revision: Apr. 25, 2016

Approved: Jul. 28, 2016

How to cite this article:

Libarodni dos Santos, J. O., Formiga, N. S., de Melo, G. F., Ramalho, M. H. S., \& Cardoso, F. L. (2017). Factorial structure validation of the Movement Assessment Battery for Children in school-age children between 8 and 10 years old. Paidéia (Ribeirão Preto), 27(68), 348-355. doi: 10.1590/1982-43272768201713 